\title{
Effect of Milling Time on Mechanical Properties of Fly Ash Incorporated Cement Mortars
}

\author{
Zaldívar-Cadena, A.A. ${ }^{1, a}$, Díaz-Peña I. ${ }^{1, b}$, González-López, J.R. ${ }^{1, \mathrm{c}}$, \\ Vázquez-Acosta F. ${ }^{1, d}$, Cruz-López A. ${ }^{1, e}$, Vázquez-Cuchillo O. ${ }^{2, \mathrm{f}}$, \\ Vázquez-Rodríguez F. ${ }^{1, g}$, Serrato-Arias L.M. ${ }^{1, \mathrm{~h}}$.
}

${ }^{1}$ Universidad Autónoma de Nuevo León, Facultad de Ingeniería Civil, Av. Universidad s/n, Cd Universitaria, San Nicolás de los Garza, Nuevo León, 66451, MÉXICO.

${ }^{2}$ Universidad Politécnica Metropolitana de Puebla, Circuito de las flores S/N, Mateo de Regil, Puebla, Puebla, MÉXICO.

bdiaz_1986@hotmail, 'rhodio@hotmail.com,'franvaz@yahoo.com.mx

eecruz_lopeza@yahoo.com.mx, ${ }^{\prime}$ odilon_vazquez_c@hotmail.com, ${ }^{9}$ fcofimeuanl@gmail.com, hluceromarisol7@gmail.com

Corresponding author: ${ }^{a}$ azaldiva70@hotmail.com

Keywords: Fly ash, Milling time, Portland cement, Mortars, Microstructure properties.

Abstract. Currently, thermal energy generation through coal combustion produces ash particles which cause serious environmental problems and which are known as Fly Ash (FA). FA main components are oxides of silicon, aluminum, iron, calcium and magnesium in addition, toxic metals such as arsenic and cobalt. The use of fly ash as a cement replacement material increases long term strength and durability of concrete. In this work, samples were prepared by replacing cement by ground fly ash in 10, 20 and $30 \%$ by weight. The characterization of raw materials and microstructure was obtained by Scanning Electron Microscopy (SEM) and X-ray diffraction (XRD). The final results showed that the grinding process significantly improves the mechanical properties of all samples when compared replacing a mortar made with cement by ground fly ash and the reference samples without added fly ash. The beneficial effect of the ground fly ash can increase the use of this product in precast concrete industry.

\section{Introduction.}

Fly ash also known as geothermal waste results from the calcination of coal in geothermal power plants because of its high content of amorphous silica can be used as a byproduct and potentially embedded in a cementitious matrix in building materials. The performance of the resulting material is linked to the chemical composition of the fly ash. In the Cerro Prieto geothermal plant in Baja California, Mexico, are generated 5000 tons per month of fly ash [1,2]. Fly ash is generated at a temperature between 1200 and $1700^{\circ} \mathrm{C}$ and according to the organic and inorganic materials contained from its geological origin around 180 individual mineral groups have been identified in its chemical composition [3]. Most of the reports in the current literature have estimated global production of ash by up to 500 million tons a year [4-6].

This paper proposes FA process through severe mechanical milling for subsequent use in Portland cement mortars and verifying its influence on the development of mechanical strength at different ages.

\section{Use of the fly ash in the building materials.}

At present, the fly ash has been used as supplementary of Portland cement material and as raw material for the production of ceramic tiles. There have been studies which have concluded that adding up to $40 \%$ fly ash as a replacement material has resulted in good mechanical and durability properties [7].

Among the techniques to increase the durability of concrete have been implemented consumption of fly ash in the cementitious matrix, resulting in a significant increase in the forecast of useful service life of the materials produced. N Bouzoubaâ et al. have found that the mechanical 
properties and durability of concrete made from this cement and fly ash were superior to those obtained without fly ash [8]. The production of concrete with high fly ash consumption therefore offer an effective improvement to the increase in the durability of concrete exposed to saline environment $[9,10]$.

However, studies where the use of fly ash subjected to severe grinding process as a replacement material are necessary due to the large use of these techniques as pozzolanic activation mechanism. Studies have focused on the effect of milling time on the average particle size wherein the average size of the fly ash significantly decreased from 36 to $5 \mu \mathrm{m}$ after $0.5 \mathrm{~h}$ of milling and only slightly from 5 to $2 \mu \mathrm{m}$ with an additional milling time of 0.5 to 96 hours because of fragmentation and agglomeration of the particles. It has also been studied, mechano-chemical activation of fly ash by adding a nitrogen source to the planetary mill obtaining good properties on surface area and porosity in comparison to conventional ash [11-13].

\section{Experimental methodology.}

Material was analyzed by testing different microstructural characterization techniques: XRD, BET, SEM-EDS, XRF and PSD. Subsequently, a grinding process by the planetary ball mill was performed for 5,10 and $15 \mathrm{~h}$ then, $5 \mathrm{~mm} \times 5 \mathrm{~mm}$ mortar specimens were manufactured with different levels of FA replacement, $10 \%, 20 \%$ and $30 \%$. \%. Lastly were performed the trials of three samples for each test age. Reference specimens were prepared with Portland cement. As shown in Figures 1 and 2.

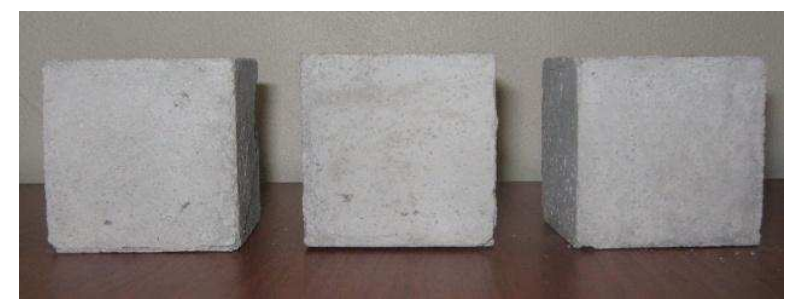

Figure 1, Reference specimens.

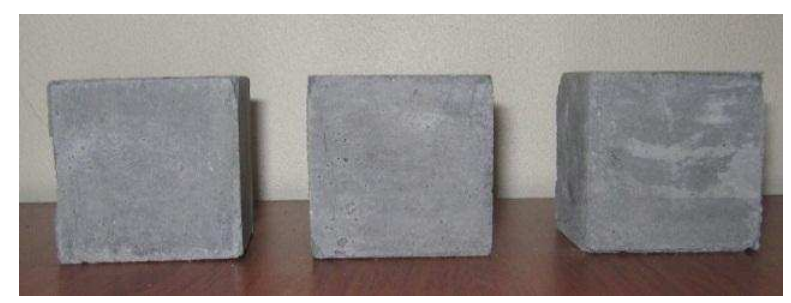

Figure 2. Test specimens with FA replacement.

\section{Results.}

\section{XRD - Fly ash}

Fly ash was analyzed using the technique of X-ray diffraction (XRD), for determination of mineralogical composition and the existence of amorphous phase. After the grinding process the raw material was again analyzed in a X-ray diffractometer model Bruker D8 Advance with Vantec detector, following the next conditions: excitation voltage of $40 \mathrm{kV}$, current $40 \mathrm{~mA}$, scanning rate $0.05(2 \theta / \mathrm{seg})$, angle $2 \theta$ between $10^{\circ}$ and $70^{\circ}$, respectively. The difractogram is shown in Figure 3. 


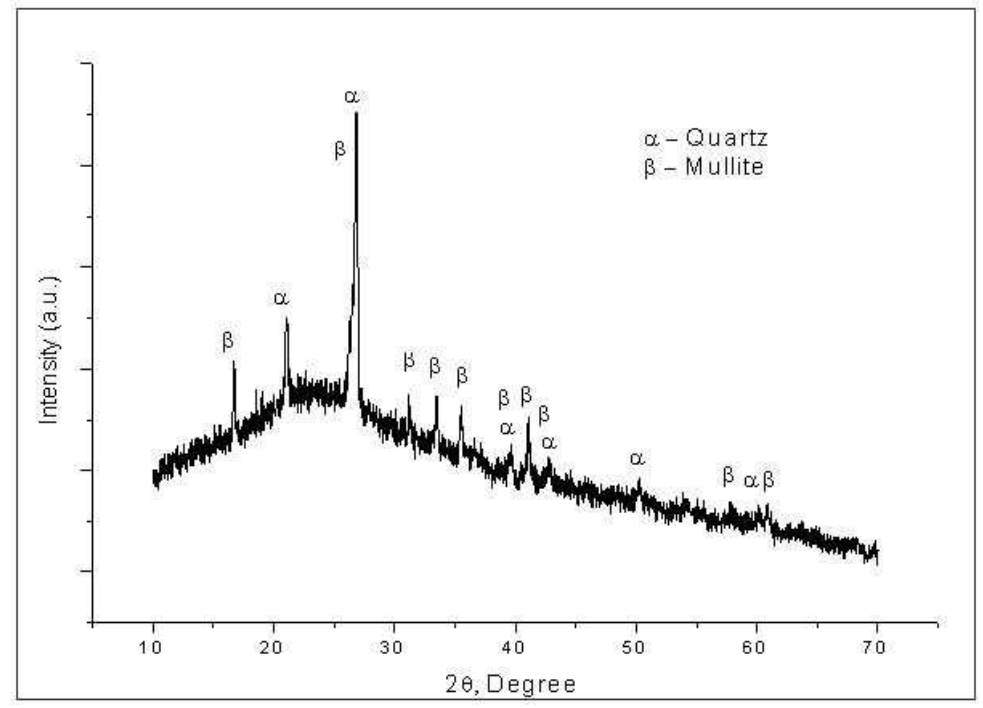

Figure 3, X-ray difractogram of the FA after mechanical grinding.

BET-Fly ash.

Once the FA ground, proceeded to analyse its surface area through equipment BET NOVA Quantachrome Instruments 2000e. Prior to the testing start was done degassing at $100{ }^{\circ} \mathrm{C}$ for one hour to ensure that all moisture has been removed. Table 1 shows the results obtained by this test.

Table.1. BET analysis of FA after milling.

\begin{tabular}{lllll}
\hline Sample & FA & FA 5 h & FA 10 h & FA 15 h \\
\hline $\mathrm{M}^{2} / \mathrm{gr}$ & 3.89 & 5.82 & 7.24 & 11.13 \\
\hline
\end{tabular}

\section{Microstructural characterization by SEM.}

Samples were coated with a thin layer of gold to make the sample more conductive and to obtain better resolution in the scanning electron microscope (SEM). Microstructure analysis was performed in a JEOL JSM-6490LV microscope coupled with Energy Dispersive X-ray Spectrometer (EDS) INCA-Sight from OXFORD instruments. FA was analyzed during different times of milling. In Figure 4, each grinding time and their respective morphology obtained from SEM are specified. It was observed that the particle size changing from $10 \mu \mathrm{m}$ to $5 \mu \mathrm{m}$ does not change after 5 hours.

\begin{tabular}{|c|c|c|c|}
\hline SEM-Fly ash & SEM-5 hours & SEM-10hours & SEM-15 hours \\
\hline & & & \\
& & & \\
& & & \\
& & & \\
& & & \\
& & & \\
& & & \\
\end{tabular}

Figure 4, Different morphologies in variation of the milling time.

\section{Compressive strength at different ages varying the substitution percentage of FA.}

Figure 5 shows an increase in mechanical properties by replacing the percentage of FA in mortars produced; correlating the XRD results, it is found that the mechanical grinding severe changes the reactivity of the FA encouraging a significant increase in mortars physical properties containing FA ground activated. 


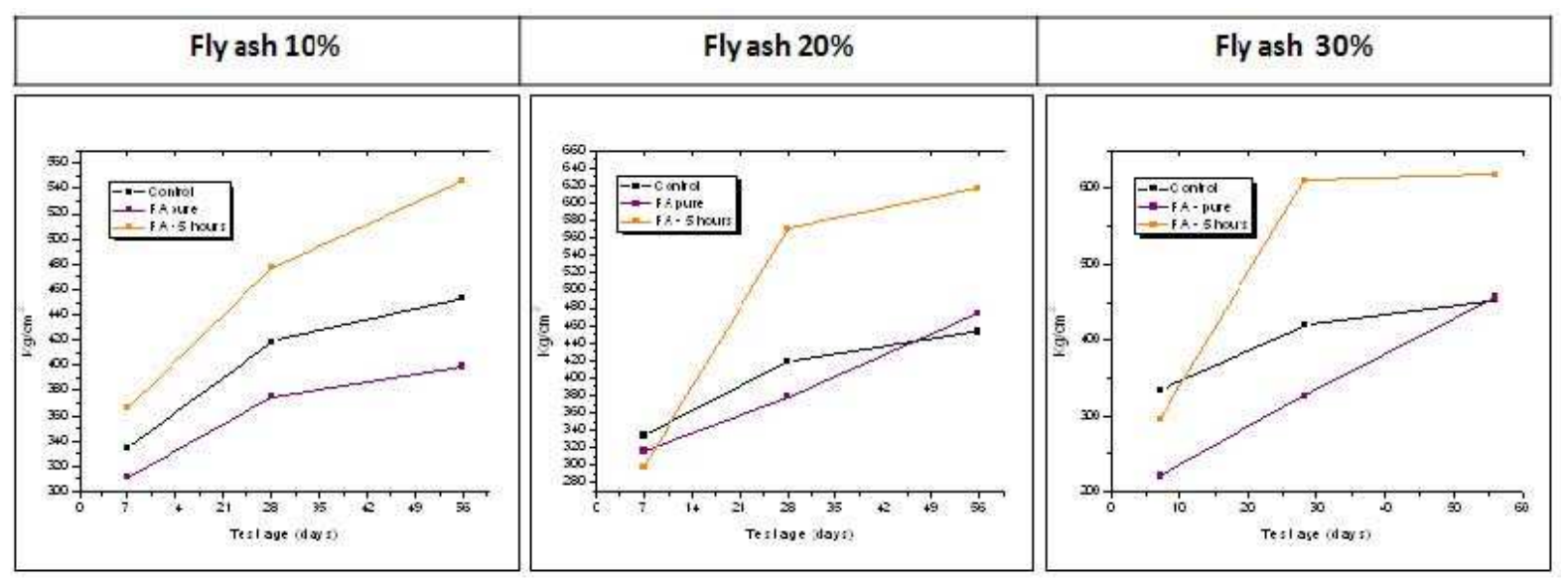

Figure 5. Improved compression resistance with variation in percentage replacement of Fly Ash.

\section{Conclusions}

$\mathrm{A} 12 \mathrm{O} 3$ and $\mathrm{SiO} 2$ phases were identified by XRD. These phases are the basis of the pozzolanic reaction with the portlandite (calcium hydroxide) which is formed in the initial hydration reaction of Portland cement, also XRD results shown that the material has amorphous phase.

It can be observed by SEM that fly ash fineness increases with ball milling treatment. The analysis shows that the BET surface area is greater in samples with longer grinding time (15 hours).

The rate of hydration of mixtures with ground fly ash content was higher in comparison with the untreated fly ash and this follows from the results of strength development.

\section{Acknowledgements}

For financial supporting CONACYT-México, Project No. 107063 and PAICYT UANL 2011-2012.

\section{References}

[1] L. Y. Gómez, J. I. Escalante, G. Mendoza. "Geothermal waste: An alternative replacement material of portland cement”. J. Mat. Sc. Vol. 39, 2004.

[2] R.S Blissett, N.a. Rowson. "A review of the multi-component utilization of coal fly ash". E. Fuel. Vol. 97, 2012.

[3] SV. Vassiliev, GS Vassileva. "Methods for characterization of composition of fly ashes from coal-fired power stations: a critical overview. E. Fuel. Vol.19, 2005.

[4] M.A Ahmaruzzaman "A review on the utilization of fly. Prog Energy Combust Sci.Vol.36, 2010.

[5] International Energy Statistics, US Energy Information Administration; 2011.http://eia.gov/cfapps/ipdbproject/iedindex3.cfm .

[6] Production and utilization of CCPs 2008 in Europe, European coal combustion association ;2008. http://www.ecoba.com/evjm,media/ccps/Ecoba_Stat_2008_EU15.pdf

[7] A. Mishulovich , J.L. Evanko "Ceramic tiles from high carbon fly ash", international ash utilization symposium, 2003.

[8] N Bouzoubaâ, M.H Zhang, V.M Malhotra"Mechanical properties and durability of concrete made with high-volume fly ahsblended cements using a coarse fly ash, Cement and Concrete Research, Volume 31, Issue 10,October 2001. 
[9] A. Duran-Herrera, D. P. Bentz, "Evaluation of sustainable high-volume fly ash concretes" CCC, Vol. 33, 2011.

[10] Bentz-Dale P. “ influence of curing conditions on water loss and hydration in cement pastes with and without fly ash subtitution" Technical Paper, NIST, 2002.

[11] Metha, PK. "High-volume fly ash concrete for sustainable development . in:Wank K, editor. International workshop on sustainable development and concrete technology. Beijing: Iowa State University Publication, 2004.

[12] Mei-Rong Wang, De-Chang Jia, Pei-Gang He, Yu Zhou," Microstructural and mechanical characterization of fly ash cenosphere/metakaolin-based geopolymeric composites", Ceramic International, Vol.37,2011.

[13] Ming-Gou Li, et al. "Effects of wet ball milling on lead stabilization and particle size variation in municipal solid waste incinerator fly ash”,J,Hazardous Materials, vol.174,2010. 